\title{
Characterization of Peptidoglycan from the Cyanelles of Cyanophora paradoxa
}

\author{
By ALASTAIR AITKEN* AND R. Y. STANIER \\ Institut Pasteur, 25 rue du Docteur Roux, 75724 Paris Cedex 15, France
}

(Received 17 October 1978)

\begin{abstract}
Peptidoglycan has been purified from the photosynthetic organelles ('cyanelles') of Cyanophora paradoxa. The results indicate the presence of $\mathrm{N}$-acetylmuramic acid, $\mathrm{N}$ acetylglucosamine, alanine, glutamic acid and diaminopimelic acid in the molar ratio of $1: 1: 1 \cdot 6: 1: 1$. The peptidoglycan may be present in a lipoprotein-peptidoglycan complex. The structure of the peptidoglycan appears to be identical to that of cyanobacteria and the other Gram-negative bacteria so far studied. Peptidoglycan was also partly purified from two species of cyanobacteria, Gloeothece 7109 and Gloeobacter violaceus. Since the genome of the cyanelle closely resembles that of chloroplasts, the results suggest that the cyanelle of Cyanophora paradoxa is an intermediate form between an endosymbiotic cyanobacterium and a chloroplast.
\end{abstract}

\section{INTRODUCTION}

The taxonomic position of Cyanophora paradoxa has been the subject of much controversy (Pickett-Heaps, 1972). The organism is a flagellated protist containing photosynthetic organelles termed cyanelles. There is much evidence to suggest that the cyanelles represent endosymbiotic cyanobacteria (Pickett-Heaps, 1972; Hall \& Claus, 1963), although the cyanelle is an obligate symbiont which has so far proved incapable of being cultured separately from the host cell. The cyanelles appear to have retained considerable autonomy. Replication of the cyanelle does not seem to be linked to host cell division (Hall \& Claus, 1963). Cyanophora paradoxa contains varying numbers of cyanelles - usually between two and four but frequently more in old cultures. The photosynthetic pigment system of cyanelles resembles that of cyanobacteria and rhodophyta (Chapman, 1966) and the fine structure of cyanelles is very similar to that of unicellular cyanobacteria (Hall \& Claus, 1963). Not all wall layers of cyanobacteria and other Gram-negative bacteria have been shown to be present in the cyanelles. Only the electron-dense layers associated with the cytoplasmic membrane and peptidoglycan components have been observed; the outer membrane layer containing lipopolysaccharide appears to be absent (Hall \& Claus, 1963; Pickett-Heaps, 1972). Schenk (1970) has shown that the wall of the cyanelles is sensitive to lysozyme.

In contrast to the evidence suggesting that the cyanelle represents an endosymbiotic cyanobacterium, Herdman \& Stanier (1977) have recently shown that the genome size of the cyanelle closely resembles that of chloroplasts. The cyanelle may therefore represent a bridge between cyanobacteria and chloroplasts. The present study is an attempt to verify the presence and investigate the structure of peptidoglycan in cyanelle walls.

* Present address: Department of Biochemistry, The University, Dundee DD1 4HN, Scotland. 


\section{METHODS}

Reagents. Enzymes were purchased from Worthington Biochemical Corp. (Freehold, N.J., U.S.A.) and chemicals for reagents and media were analytical grade from usual suppliers.

Organism. Cyanophora paradoxa, obtained from Professor L. Provasoli, was grown in batch culture for about $15 \mathrm{~d}$ in six 41 bottles at $18{ }^{\circ} \mathrm{C}$, bubbled with a slow stream of air/ $\mathrm{CO}_{2}(99: 1, \mathrm{v} / \mathrm{v})$ on a light-dark cycle of $18: 6 \mathrm{~h}$. The light intensity was approximately 2000 lux. The culture medium was as described by Herdman \& Stanier (1977) except that the trace metal mix was replaced by the cyanobacterial trace metal mix $A_{5}$ of Stanier et al. (1971). $\mathbf{A}_{5}$ contains similar amounts of the trace metals with molybdate and copper ions in addition.

Preparation of cyanelles. The culture was harvested by centrifugation at about $500 \mathrm{~g}$ for $10 \mathrm{~min}$. Under these conditions pelleting of $C$. paradoxa was incomplete, but centrifugation at higher speeds generally caused considerable premature lysis of the organism which made subsequent manipulations more difficult. A yield of about $1 \mathrm{~g} \mathrm{l}^{-1}$ was generally obtained. Before harvesting, each bottle of culture was carefully examined under the microscope for the presence of bacteria.

The pellets of $C$. paradoxa, in $4 \mathrm{~g}$ amounts, were resuspended thoroughly by pipette followed by vortex mixing in $20 \mathrm{ml} 50 \mathrm{~mm}$-phosphate buffer (pH 7.0) containing $0.5 \mathrm{M}$-sucrose. After $10 \mathrm{~min}$ at $4{ }^{\circ} \mathrm{C}$ the suspension was centrifuged at $350 \mathrm{~g}$ and the eukaryotic cells were lysed by thorough resuspension, as before, in buffered $0.2 \mathrm{M}$-sucrose at $4{ }^{\circ} \mathrm{C}$. Intact cyanelles were separated from cell debris by careful centrifugation at low speed; generally $300 \mathrm{~g}$ for $8 \mathrm{~min}$ proved sufficient to pellet most of the cyanelles, leaving most of the eukaryotic cell debris in suspension. Each stage of the osmotic shock treatment and subsequent washing was monitored under the microscope. If, as occasionally occurred, cyanelles and debris tended to clump together making resuspension and removal of debris difficult, DNAase $\left(200 \mu \mathrm{g} \mathrm{ml}^{-1}\right.$ in $\left.5 \mathrm{~mm}-\mathrm{MgCl}_{2}\right)$ was added and incubated for $30 \mathrm{~min}$ in the cold. The washing procedure was repeated until the cyanelle preparation appeared fairly clean (usually five to six washings). The cyanelles were stored frozen until required.

Preparation of cyanelle walls. Initially the walls of the cyanelles were purified by methods modified from those of Weidel et al. (1960) which involved phenol extraction of the lysed cyanelles. This preparation was digested with trypsin $\left(250 \mu \mathrm{g} \mathrm{ml}^{-1}\right)$ in ammonium acetate buffer $(50 \mathrm{mM} ; \mathrm{pH} 8.5)$ for $3 \mathrm{~h}$ at $37^{\circ} \mathrm{C}$ with continuous shaking followed by centrifugation at $6000 \mathrm{~g}$ for $10 \mathrm{~min}$.

Subsequent preparations of peptidoglycan involved treatment with sodium dodecyl sulphate (SDS) and pronase digestion. Optimum conditions were as follows. Cyanelles (approximately $10 \mathrm{~g}$ fresh wt) were broken in a French press at high pressure $(140 \mathrm{MPa})$ and centrifuged $(25000 \mathrm{~g}$ for $1 \mathrm{~h})$. The pellet was resuspended in water $(20 \mathrm{ml})$ and SDS was added to a final concentration of $4 \%(\mathrm{w} / \mathrm{v})$. This suspension was sonicated for $10 \times 2$ min periods; it was allowed to warm up to about $45^{\circ} \mathrm{C}$ during the sonication and was maintained at about this temperature by cooling in an ice bath when necessary. The suspension was then centrifuged ( $30000 \mathrm{~g}$ for $30 \mathrm{~min}$ ) and the pellet was resuspended in $2 \%$ SDS by means of a vortex mixer followed by brief sonication to ensure complete resuspension. This mixture was centrifuged $(1000 \mathrm{~g}$ for $10 \mathrm{~min})$ and the pellet was retained. The supernatant was then recentrifuged $(30000 \mathrm{~g}$ for $30 \mathrm{~min})$ to sediment the cyanelle walls. The wall preparation was washed twice by resuspending in $20 \mathrm{ml}$ water and centrifuging at $30000 \mathrm{~g}$ for $30 \mathrm{~min}$.

Peptidoglycan was further purified by removal of associated protein by pronase digestion. During these procedures all enzyme solutions and buffers used were sterilized to avoid the possibility of bacterial contamination. The pellet of wall material was resuspended in Tris/ $\mathrm{HCl}$ buffer $(6 \mathrm{ml} ; 10 \mathrm{mM} ; \mathrm{pH} 7 \cdot 5)$, filtersterilized pronase solution $\left(0.2 \mathrm{ml} ; 2 \mathrm{mg} \mathrm{ml}^{-1}\right)$ was added, and the suspension was incubated for $16 \mathrm{~h}$ at $37^{\circ} \mathrm{C}$ with continuous shaking. The peptidoglycan, recovered by centrifuging $(30000 \mathrm{~g}$ for $40 \mathrm{~min})$, was resuspended in SDS $(10 \mathrm{ml} ; 2 \%, \mathrm{w} / \mathrm{v})$ and briefly sonicated to ensure complete dispersion. The suspension was centrifuged at low speed $(1000 \mathrm{~g}$ for $10 \mathrm{~min})$ and the pellet was retained. The supernatant was centrifuged at high speed $(30000 \mathrm{~g}$ for $30 \mathrm{~min}$ ) and this pellet was washed twice with water by resuspension in a vortex mixer followed by centrifugation as before. The pellet, which contained most of the peptidoglycan, was resuspended in water for analysis. The other fractions from low-speed centrifugation were also examined qualitatively for the presence of peptidoglycan components. After pronase treatment the pellets were very flocculant. Prolonged sonication and SDS treatment followed by repeated washing at this stage was found to render the preparations in a form which was difficult to sediment. Wall preparations at an intermediate stage of purification and purified peptidoglycan were stored frozen at $-20^{\circ} \mathrm{C}$.

Small amounts (approximately $5 \mathrm{~g}$ ) of two species of cyanobacteria, Gloeothece 7109 and Gloeobacter violaceus, were treated in parallel with the cyanelles. These peptidoglycan preparations were not carried through to a high degree of purity but were intended to serve as a form of control.

Digestion with lysozyme. The cyanelle wall preparation obtained after phenol and trypsin treatment was suspended in $20 \mathrm{ml}$ ammonium acetate buffer $(50 \mathrm{~mm}$; pH 7.4) by brief sonication and centrifuged at 
$30000 \mathrm{~g}$ for $10 \mathrm{~min}$. The pellet was resuspended in the same buffer and $10 \mathrm{mg}$ lysozyme was added. The suspension was incubated at $37^{\circ} \mathrm{C}$ with continuous shaking for $4 \mathrm{~h}$; then a further $5 \mathrm{mg}$ lysozyme was added and incubation was continued for $16 \mathrm{~h}$. After centrifuging ( $20000 \mathrm{~g}$ for $30 \mathrm{~min}$ ), the supernatant was freezedried, redissolved in formic acid ( $2 \mathrm{ml} ; 50 \%, \mathrm{v} / \mathrm{v})$ and chromatographed on a column of Sephadex G-25 superfine $(95 \times 0.8 \mathrm{~cm})$. Fractions of $1.2 \mathrm{ml}$ were collected. Samples $(50 \mu \mathrm{l})$ of the appropriate fractions were analysed by descending paper chromatography (Whatman no. 1 paper) in 1-butanol/water/glacial acetic acid (4:5:1, by vol; upper phase) for $24 \mathrm{~h}$ (Primosigh et al., 1961). Fractions containing ninhydrin-positive material of the appropriate size range and $R_{\mathrm{F}}$ value of subunits of peptidoglycan (Primosigh et al., 1961; Hocht et al., 1965) were pooled, freeze-dried and redissolved in ethanol $(2 \times 2 \mathrm{ml} ; 85 \%$, v/v). Insoluble material was removed by centrifugation and the ethanol-soluble material was chromatographed (Whatman no. 3 paper) under the conditions described above. Markers were located with ninhydrin and the main, unstained bands of ninhydrin-positive material were eluted with $1 \mathrm{M}$-acetic acid. Samples were analysed qualitatively after hydrolysis $\left(4 \mathrm{M}-\mathrm{HCl} ; 20 \mathrm{~h}\right.$ at $\left.110^{\circ} \mathrm{C}\right)$ and dansylation.

Initially, descending chromatography using the solvent system (Primosigh et al., 1961) 1-butanol/pyridine/ water/glacial acetic acid (60:40:30:3, by vol.) was used to separate the hydrolysed peptidoglycan preparations. Chromatograms were run for $40 \mathrm{~h}$ and developed with ninhydrin. Subsequently dansylation of the hydrolysate followed by thin-layer chromatography was used for qualitative analysis of preparations. The amino acids and amino sugars in the hydrolysate were labelled by the addition of dansyl chloride (Gray, 1972). The products were spotted on to polyamide sheets $(7.5 \times 7.5 \mathrm{~cm})$ and the mixture of dansyl derivatives was resolved with the following solvents: (i) $4 \%$ (v/v) formic acid; (ii) toluene/acetic acid $(9: 1$, by vol.); (iii) ethyl acetate/methanol/acetic acid (20:1:1, by vol.). Standard samples of diaminopimelic acid, muramic acid and glucosamine were treated identically to peptidoglycan samples. Fractions which appeared pure were subsequently analysed quantitatively.

Analysis of peptidoglycan. Samples of cyanelle wall preparations and purified products of lysozyme digestion were hydrolysed in $3.3 \mathrm{M}-\mathrm{HCl}$ for $14 \mathrm{~h}$ at $110^{\circ} \mathrm{C}$ for amino sugars and in $6 \mathrm{M}-\mathrm{HCl}$ for $24 \mathrm{~h}$ at $110^{\circ} \mathrm{C}$ for amino acids. These were identified on a JEOL JLC-5AH amino acid analyser with the following programme. Glucosamine was identified on the short column equilibrated with $\mathrm{pH} 5.26$ buffer where it eluted $11 \mathrm{~min}$ before lysine. The long column was run at $45^{\circ} \mathrm{C}$ for $30 \mathrm{~min}$ before the temperature was increased to $55^{\circ} \mathrm{C}$. The $\mathrm{pH} 3.32$ buffer was changed to $\mathrm{pH} 4.17$ after $100 \mathrm{~min}$. Under these conditions muramic acid eluted between, and was well separated from, serine and glutamic acid. Glucosamine eluted (as a broad peak) after methionine and before the buffer change. Diaminopimelic acid eluted immediately after the buffer change and before isoleucine. The hydrolysates were also analysed on a Multichrom amino acid analyser with a single column programme as follows. The buffer $(\mathrm{pH} 3 \cdot 18)$ was changed to $\mathrm{pH} 4 \cdot 25$ after $115 \mathrm{~min}$ then to $\mathrm{pH} 5.28$ after a further $115 \mathrm{~min}$. The temperature was increased from 45 to $54^{\circ} \mathrm{C}$ after $45 \mathrm{~min}$ and then to $65^{\circ} \mathrm{C}$ after a further $157 \mathrm{~min}$. In this programme glucosamine and galactosamine eluted in that order between phenylalanine and histidine. All components were well separated except for diaminopimelic acid which was not resolved from methionine.

Standard samples of glucosamine, galactosamine, muramic acid and diaminopimelic acid were run individually and together with a standard mixture of protein amino acids that included the internal standard norleucine. No corrections were made for losses due to hydrolysis.

\section{RESULTS AND DISCUSSION}

The analysis results, expressed as molar ratios, for cyanelle peptidoglycan after hydrolysis in $3.3 \mathrm{M}-\mathrm{HCl}$ and $6 \mathrm{M}-\mathrm{HCl}$ for $14 \mathrm{~h}$ and $24 \mathrm{~h}$, respectively, are shown in Table 1.

Prolonged treatment of the crude cyanelle wall preparations with large amounts of lysozyme $(15 \mathrm{mg})$ and subsequent gel filtration and paper chromatography proved insufficient to purify completely the subunits of the peptidoglycan. The wall preparations used in this experiment contained large amounts of proteinaceous material even after the mild trypsin treatment.

Gel filtration on Sephadex G-25 of the peptidoglycan after lysozyme treatment indicated that at least some of the peptidoglycan occurs in the form of low molecular weight subunits and that crosslinking of the peptide chains is incomplete in the cyanelle polymer, as in a typical Gram-negative peptidoglycan (Ghuysen \& Shockman, 1973).

It seems certain that there were substantial amounts of protein covalently attached to the peptidoglycan since neither phenol nor hot SDS treatment combined with sonication was sufficient to remove non-peptidoglycan amino acids from the wall preparations.

The peptidoglycan prepared by phenol extraction also contained galactosamine. This 
Table 1. Amino acid analyses of peptidoglycan (molar ratios)

\begin{tabular}{|c|c|c|c|c|}
\hline & \multicolumn{2}{|c|}{ Cyanelle peptidoglycan } & \multirow[b]{2}{*}{$\begin{array}{c}\text { Gloeothece } \\
\text { (phenol and } \\
\text { SDS } \\
\text { treatment) }\end{array}$} & \multirow[b]{2}{*}{$\begin{array}{c}\text { Gloeobacter } \\
\text { (phenol } \\
\text { extraction)* }\end{array}$} \\
\hline & $\begin{array}{c}\text { Hydrolysed } \\
\text { with } \\
3.3 \mathrm{M}-\mathrm{HCl}\end{array}$ & $\begin{array}{c}\text { Hydrolysed } \\
\text { with } \\
6 \mathrm{M}-\mathrm{HCl}\end{array}$ & & \\
\hline Glucosamine & $0 \cdot 83$ & $0 \cdot 45$ & $1 \cdot 00$ & $0 \cdot 6$ \\
\hline Galactosamine & 0 & 0 & $0.85 \dagger$ & 0.7 \\
\hline Lysine & 0.04 & 0.04 & 0.67 & + \\
\hline Arginine & 0 & 0 & $6 \cdot 16$ & + \\
\hline Aspartic acid & 0.05 & 0.04 & $6 \cdot 46$ & + \\
\hline Threonine & 0.02 & 0.05 & $0 \cdot 68$ & + \\
\hline Serine & $0 \cdot 1$ & 0.07 & $1 \cdot 3$ & + \\
\hline Muramic acid & $0 \cdot 71$ & $0 \cdot 21$ & 0.61 & $1 \cdot 00$ \\
\hline Glutamic acid & $1 \cdot 00$ & 1.00 & $1 \cdot 86$ & + \\
\hline Glycine & $0 \cdot 1$ & 0.08 & $1 \cdot 83$ & + \\
\hline Alanine & $1 \cdot 45$ & $1 \cdot 57$ & $2 \cdot 23$ & + \\
\hline Valine & 0 & 0 & $0 \cdot 38$ & + \\
\hline Methionine & 0 & 0 & 0.77 & + \\
\hline Diaminopimelic acid & $1 \cdot 09$ & 0.99 & $1 \cdot 22$ & $1 \ddagger$ \\
\hline Isoleucine & 0 & 0 & $1 \cdot 72$ & + \\
\hline Leucine & 0 & 0.05 & $1 \cdot 34$ & + \\
\hline Phenylalanine & 0 & 0 & $0 \cdot 24$ & + \\
\hline
\end{tabular}

amino sugar was not detected in any preparation after SDS treatment although galactosamine has been shown to be present in some preparations of cyanobacterial peptidoglycans (Drews \& Meyer, 1964; Hocht et al., 1965), including those of the two cyanobacteria in this study (Table 1). There was insufficient material to look for the presence of neutral sugars in the preparations.

Analysis of the wall preparations of Gloeothece 7109 and Gloeobacter violaceus (Table 1) indicated that diaminopimelic acid, $\mathrm{N}$-acetylglucosamine and $\mathrm{N}$-acetylmuramic acid are present in their peptidoglycans in a molar ratio of $1: 1: 1$. These two species were chosen (although only small amounts were available) because the walls of cyanobacteria of these types had not previously been examined for peptidoglycan components. Gloeothece species are sheathed unicellular cyanobacteria (Stanier et al., 1971) and, as expected, the purification of peptidoglycan did not prove easy. Gloeobacter violaceus is an unusual cyanobacterium which lacks thylakoids (Rippka et al., 1974) and it was possible that, like the membrane organization, the wall may have differed in this organism.

The results obtained in this study verify the presence of a peptidoglycan component in the walls of the cyanelles of Cyanophora paradoxa and suggest that the structure of the peptide is similar to that of cyanobacteria and other Gram-negative bacteria so far examined. The implied molar ratio of $N$-acetylglucosamine: $N$-acetylmuramic acid:alanine: glutamic acid:meso-diaminopimelic acid of $1: 1: 1 \cdot 6: 1: 1$ (see Table 1) corresponds well with results reported by others (for example, Drews \& Meyer, 1964; Hocht et al., 1965; Braun \& Sieglin, 1970), who found a molar ratio of between 1.6 and 2 for alanine in Gram-negative bacteria.

The size of the DNA genome in the cyanelle resembles that of a chloroplast (Herdman \& Stanier, 1977). The cyanelle may therefore be considered an intermediate form between an endosymbiotic cyanobacterium and a chloroplast. The proof of the presence of peptidoglycan in the cyanelle walls together with the genetic resemblance between the cyanelle and the chloroplast strongly support the endosymbiotic hypothesis concerning the origin of the chloroplast (Marguilis, 1970). 
We would like to thank F. Schaeffer for instruction in the preparation of cyanelles and G. Le Bras for performing amino acid analyses. This work was carried out during the tenure by A.A. of a Royal Society European Exchange Fellowship.

\section{REFERENCES}

Braun, V. \& SiEglin, U. (1970). The covalent murein-lipoprotein structure of the $E$. coli cell wall. European Journal of Biochemistry 13, 336346.

Chapman, D. J. (1966). Pigments of the symbiotic algae (cyanosomes) of Cyanophora paradoxa and Glaucocystis nostochinearum and two Rhodophyceae Porphyridium aerugineum and Asterocystis ramosa. Archiv für Mikrobiologie 55, 17-25.

DREWS, G. \& MEYER, H. (1964). Untersuchungen zum chemischen Aufbau der Zellwande von Anacystis nidulans und Chlorogloea fritschii. Archiv für Mikrobiologie 48, 259-267.

GHuysen, J. M. \& SHOCKman, G. D. (1973). Biosynthesis of peptidoglycan. In Bacterial Membranes and Walls, pp. 37-130. Edited by L. Leive. New York: Marcel Dekker.

GrAY, W. R. (1972). End-group analysis using dansyl chloride. Methods in Enzymology 25, 121-143.

Hall, W. T. \& Claus, G. (1963). Ultrastructural studies on the blue-green algal endosymbiont in Cyanophora paradoxa Korschikoff. Journal of Cell Biology 19, 551-563.

Herdman, M. \& Stanier, R. Y. (1977). The cyanelle: chloroplast or endosymbiotic prokaryote? FEMS Microbiology Letters 1, 7-12.

Hocht, M., Martin, H. H. \& Kandler, O. (1965).
Zur Kenntnis der chemischen Zusammensetzung der Zellwande der Blaualgen. Zeitschrift für Pflanzenphysiologie 53, 39-57.

MARGUiLIs, L. (1970). Origin of Eukaryotic Cells. New Haven, U.S.A.: Yale University Press.

PicketT-Heaps, J. (1972). Cell division in Cyanophora paradoxa. New Phytologist 71, 561-567.

Primosigh, J., Pelzer, H., MaAss, D. \& Weidel, W. (1961). Chemical characterization of mucopeptides released from the $E$. coli cell wall by enzymic action. Biochimica et biophysica acta 46, 68-80.

RipPKa, R., Waterbury, J. \& Cohen-Bazire, G. (1974). A cyanobacterium which lacks thylakoids. Archives of Microbiology 100, 419-436.

Schenk, H. E. A. (1970). Nachweis einer lysozymempfindlichen Stutzmembran der Endocyanellen von Cyanophora paradoxa Korschikoff. Zeitschrift für Naturforschung 25 b, 656.

Stanier, R. Y., Kunisawa, R., Mandel, M. \& Cohen-Bazire, G. (1971). Purification and properties of unicellular blue-green algae (order Chroococcales). Bacteriological Reviews 35, 171205.

Weidel, W., Frank, H. \& Martin, H. H. (1960). The rigid layer of the cell wall of $E$. coli strain B. Journal of General Microbiology 22, 158-166. 